\section{(6) OPEN ACCESS}

\title{
Bed-sharing and risk of hospitalisation due to pneumonia and diarrhoea in infancy: the 2004 Pelotas Birth Cohort
}

\author{
Kátia M A Ngale, ${ }^{1}$ Iná S Santos, ${ }^{1}$ David A González-Chica, ${ }^{2}$ Aluísio J D de Barros, ${ }^{1}$ \\ Alicia Matijasevich $^{1}$
}

- Additional supplementary tables are published online only. To view these files please visit the journal online (http:// dx.doi.org/10.1136/jech-2012201145).

${ }^{1}$ Postgraduate Epidemiology Program, Federal University of Pelotas, Pelotas, RS, Brazil ${ }^{2}$ Postgraduate Nutrition Program, Federal University of Santa Catarina, Florianópolis, SC, Brazil

\section{Correspondence to}

Dr Iná S Santos, Programa de Pós-graduação em Epidemiologia, Universidade Federal de Pelotas, Rua Marechal Deodoro,

$1160-3$ piso, Pelotas, RS 96020-220, Brazil; inasantos@uol.com.br

Accepted 6 September 2012 Published Online First 24 October 2012

\author{
ABSTRACT \\ Objective To investigate the association between bed- \\ sharing with the mother at 3 months of age and \\ incidence of hospitalisation due to pneumonia and \\ diarrhoea between 3 and 12 months.
}

Methods The 2004 Pelotas Birth Cohort included all live births to mothers living in Pelotas, Brazil, in 2004. Information on bed-sharing was obtained at the 3-month follow-up visit, and on hospitalisations at the 12-month visit, both based on mothers' reports. Only singleton infants with complete information on hospitalisation were analysed.

Results 3906 infants were included. The bed-sharing prevalence at 3 months was $46.4 \%(95 \% \mathrm{Cl}$ 44.9 to $48.0 \%)$. The incidence of pneumonia admissions between 3 and 12 months was $3.6 \%(95 \% \mathrm{Cl} 3.3$ to $4.2 \%$ ) and diarrhoea, $0.9 \%$ (95\% Cl 0.6 to $1.2 \%$ ). In crude analyses, bed-sharing with the mother was associated with higher incidence of hospitalisation due to both pneumonia and diarrhoea. There was interaction between bed-sharing and duration of breastfeeding regarding the chance of admission due to pneumonia. Among infants breastfed for 3 months or less, the chance of hospitalisation due to pneumonia among bedsharers was almost twice as high as among non-bedsharers (adjusted OR 1.96; 95\% Cl 1.08 to 3.55). There was no association between bed-sharing and hospitalisation due to pneumonia among infants breastfed for longer than 3 months in crude or adjusted analyses. The association between bed-sharing and admissions due to diarrhoea lost statistical significance after allowing for confounders.

Conclusions The effect of bed-sharing in infancy on the risk of hospitalisation due to pneumonia depends on breastfeeding, such that weaned children present higher risk.

\section{INTRODUCTION}

Bed-sharing is defined as a sleeping arrangement in which the child shares the same surface with another person. ${ }^{1}$ Bed-sharing with the mother generally starts soon after birth and is often extended as a child-rearing routine. It is culturally accepted within many societies, ${ }^{2}$ but the real prevalence of bed-sharing is difficult to determine because of different child ages studied. In epidemiological studies conducted in Southern Brazil, ${ }^{3} 4$ Switzerland, ${ }^{5}$ England ${ }^{6}$ and the USA, ${ }^{7}$ the prevalence of bed-sharing at about 3 months of age has ranged from $6 \%{ }^{5}$ to $44 \%{ }^{3}$

Among the benefits for the child from bedsharing, greater cardiorespiratory stability and oxygenation, diminished numbers of crying episodes, better thermoregulation and increased prevalence and duration of breastfeeding have been described. $^{8-10}$ However, the American Academy of Paediatrics has discouraged the practice of bedsharing for infants, given the possible risk of accidental suffocation, entrapment and sudden infant death syndrome, and recommends that infants should be placed to sleep in a separate but proximate sleep environment. ${ }^{11}$ Despite this recommendation, there are no studies exploring the effect of bed-sharing on severe infant morbidity in the literature.

Because heavy doses of infective agents can be expected from prolonged contact with an infectious member of the household, several studies have explored domestic crowding as a risk factor for incidence of the leading causes of hospitalisation in infancy (pneumonia and diarrhoea). Although there is no unanimity regarding the findings, several studies have shown that large numbers of individuals in the household and people sharing the infant's bedroom increase the risk of incidence of lower respiratory infections. ${ }^{12-15}$ In the case of diarrhoea, crowding has been investigated as an indicator of low socioeconomic status of the child's family and some studies have found a positive association. $^{16} 17$

The present study was planned to investigate the effect of bed-sharing with the mother (in a setting where this practice is highly prevalent) on the incidence of hospitalisations due to pneumonia and diarrhoea between 3 and 12 months of age, among infants from the 2004 Pelotas Birth Cohort.

\section{MATERIALS AND METHODS}

This was a population-based birth cohort study conducted in Pelotas, a city with about 320000 inhabitants located in Southern Brazil. The methodology of the Pelotas Birth Cohort of 2004 can be found detailed in another published paper. ${ }^{18}$ In brief, all births between 1 January 2004 and 31 December 2004, to mothers living in the urban area of Pelotas and in Jardim América (an urban district contiguous with Pelotas), at the five hospitals with maternity facilities in the city, were included in the cohort $(n=4231)$. A total of 82 infants died within the first 12 months of life (66 in the first 3 months). At 3 and 12 months after birth, the cohort members were visited at home: on these occasions, 3985 and 3907 infants, respectively, were assessed.

The perinatal assessment, conducted not more than $24 \mathrm{~h}$ after birth, was accomplished at the 
hospital of delivery. Trained interviewers conducted the perinatal interview and the newborn evaluation, using a structured questionnaire. Information on the following maternal characteristics was collected: skin colour (classified by the interviewer on the basis of observation), age, schooling level in completed years, living with or without a partner, parity (number of previous deliveries, including both live births and stillbirths), smoking (smokers defined as those who smoked every day, independent of the number of cigarettes, during any of the trimesters of pregnancy), reported history of asthma, interval between births (calculated as the time difference between the delivery of the cohort infant and the previous one), and weight gain during pregnancy (difference in weight from the start to the end of the pregnancy, as transcribed from the antenatal card, when available, or reported by the mother).

With regard to the family characteristics, the mothers were asked about their monthly income in minimum wages, the total number of people living in the home and the father's schooling level in completed years. The infant's sex, gestational age, birth weight and type of delivery (normal or caesarean) were collected by the study team at the hospital of birth. The gestational age was calculated by using the algorithm proposed by the National Health Statistics Center, using an estimated age based on the date of the last period (DLP), whenever this was available and consistent with birth weight, length and head circumference, in accordance with the normal curves for these parameters for each week of gestational age. When the gestational age based on DLP was unknown or inconsistent, a clinical estimate of maturity based on the Dubowitz method ${ }^{19}$ and on ultrasound (when available) was used. Newborns with a gestational age of less than 37 weeks were classified as preterm. The adequacy of weight for gestational age at birth was determined by means of comparison with the Williams curve $^{20}$ : those with weight lower than the 10th percentile for the gestational age at birth, in relation to those of the same sex, were classified as small for gestational age (SGA). Newborns weighing less than $2500 \mathrm{~g}$ were classified as presenting low birth weight (LBW).

At the 3- and 12-month visits, all infants were assessed using a structured questionnaire that was applied to the mother by trained interviewers. From the 3-month follow-up, the following variables were used: weight, length and breastfeeding (yes/no). Weight-for-age (WAZ), length-for-age (LAZ) and weight-forlength (WLZ) Z-scores and SD were calculated in accordance with the WHO growth curves using the WHO statistical package (http://www.who.int/childgrowth/software/en/). WAZ, LAZ and WLZ below -2 SD were classified as deficits in WAZ, LAZ and WLZ, respectively.

Bed-sharing at 3 months was defined as 'habitual sharing of the bed between the infant and the mother, for sleeping, for part of the night or the whole night'. At the 12-month follow-up, the mothers were asked about hospitalisations of the infant (yes, no) and causes of admission between the ages of 3 and 12 months. For the present analysis, the outcomes were hospitalisations due to pneumonia or diarrhoea (yes/no), independent of the number of hospitalisations.

The questionnaire used for maternal interviews at the 3- and 12 -month visits included questions on the duration of breastfeeding and the ages at which different types of foods were introduced on a regular basis. To avoid recall bias, weaning age was based on data collected when the children were 12 months old. In the current analyses, the breastfed category included infants receiving any pattern of breast milk: exclusive breastfeeding (breastfed infants that were not fed any other fluids or solids); predominant breastfeeding (breastfed infants that were also fed other fluids, such as water or tea, but who were not fed solid or semi-solid foods); or partial (infants that were fed breast milk complemented with other types of milk, such as cow's milk or formula, or with solid or semi-solid foods). Weaning was defined as the total cessation of breastfeeding. The total duration of breastfeeding was further dichotomised as $\leq 3$ and $>3$ months.

Only singleton infants with complete information about hospitalisation during the first year of life were included in the analyses. The data analyses were performed using STATA V.11.0. The independent effect of bed-sharing on hospitalisations between 3 and 12 months was assessed using multivariable logistic regression. For the analyses, a hierarchical model was used to control for potential confounders and only variables associated with bed-sharing and hospitalisation presenting $\mathrm{p}<0.2$ were kept in the regression. OR and 95\% CI were calculated. The study had a power of $80 \%$ or more to detect $R R \geq 2.0$ for the association between bed-sharing and hospitalisation due to pneumonia and $R R \geq 2.5$ for bed-sharing and hospitalisation due to diarrhoea, with significance at $\alpha<0.05$.

The perinatal study and follow-ups for the 2004 Pelotas Birth Cohort had been approved by the Research Ethics Committee of the Federal University of Pelotas. Written informed consent was obtained from the mothers before the interview and infant assessment.

\section{RESULTS}

The prevalence of bed-sharing at the age of 3 months was $46.4 \%$ (95\% CI 44.9 to $48.0 \%$ ) and was associated with nonwhite skin colour, adolescent mothers (<20 years), lower family income, mothers living without a partner, low level of parental education, higher maternal parity, short interval between deliveries, low weight gain during pregnancy, greater number of people in the household, maternal smoking and maternal history of asthma (see online supplementary table S1). Bed-sharing was also associated with the following infant characteristics: non-white skin colour, normal delivery, preterm birth and SGA, with WAZ and LAZ deficits $(<-2$ SD) at age of 3 months. Bed-sharing was higher among infants breastfed for longer than 3 months of age.

The incidence of admissions due to pneumonia between 3 and 12 months of age was 3.6\% (95\% CI 3.3 to 4.2$)$ and due to diarrhoea over the same period, $0.9 \%$ (95\% CI 0.6 to 1.2 ). Greater incidence of hospitalisation due to pneumonia (see online supplementary table S2) and due to diarrhoea (see online supplementary table S3) was associated with lower family income, lower maternal and paternal schooling level, SGA at birth, WAZ deficit $(<-2$ SD) at the age of 3 months, and early weaning (breastfeeding duration $\leq 3$ months).

In addition, the incidence of admissions due to pneumonia was associated with maternal skin colour (higher among infants of non-white mothers), parity (higher with increasing parity), smoking, maternal history of asthma and living in households with a greater number of people. LBW, prematurity, WAZ, LAZ and WLZ deficits (<-2 SD) at 3 months and early weaning ( $\leq 3$ months) were also associated with admissions due to pneumonia (see online supplementary table S2). Shorter interval between deliveries ( $<24$ months) was associated with hospitalisation due to diarrhoea (see online supplementary table S3).

Among infants who shared the bed, the incidence of hospitalisation due to pneumonia was around $4.6 \%$, vs $2.8 \%$ among those who were not bed-sharers $(p=0.003)$ (see online 
supplementary table S2). Regarding hospitalisation due to diarrhoea, the incidence among bed-sharers (1.2\%) was almost twice as high as among those who were not bed-sharers $(0.6 \%)$ $(p=0.04)$ (see online supplementary table S3).

The crude OR for hospitalisation due to pneumonia was $69 \%$ higher among bed-sharers than among non-bed-sharers $(\mathrm{OR}=1.69$; 95\% CI 1.19 to 2.39). The crude effect of bedsharing disappeared when adjusted in a model containing all other covariables except breastfeeding ( $\mathrm{OR}=1.37$; 95\% CI 0.94 to 2.00). However, when breastfeeding was included in the adjusted model, the negative effect of bed-sharing was recovered at a magnitude similar to what was observed in the crude analysis $(\mathrm{OR}=1.56$; 95\% CI 1.06 to 2.29$)$. There was an interaction between bed-sharing and duration of breastfeeding with regard to the chance of admission due to pneumonia $(p=0.08)$.

Further analyses were then stratified according to the duration of breastfeeding ( $\leq 3$ months or $>3$ months): among nonbreastfed infants, those who were bed-sharers had an OR for hospitalisation that was almost twice as high as the chance among non-bed-sharers, even after allowing for confounders (family income, maternal schooling, weight gain during pregnancy, total number of people living in the home, maternal history of asthma, gestational age at birth, SGA, and WAZ, LAZ and WLZ scores) (adjusted $O R=1.96$; 95\% CI 1.08 to 3.55) (figure 1). Among infants who were breastfed for more than 3 months, the effect of bed-sharing was not significant (adjusted $\mathrm{OR}=1.09 ; 95 \%$ CI 0.63 to 1.88 ).

In the crude analysis, the chance of hospitalisation due to diarrhoea among bed-sharers was twice as high as among non-bed-sharer infants ( $O R=2.04 ; 95 \%$ CI 1.00 to 4.17 ) (see online supplementary table S3). After adjustment for confounding (maternal age and schooling, interval between deliveries, weight gain during pregnancy, total number of people living in the home, SGA, WAZ and WLZ scores at 3 months and duration of breastfeeding), the OR fell to 1.44 (95\% CI 0.62 to 3.32 ) and statistical significance was lost (table 1). In this case, there was no evidence of interaction with the duration of breastfeeding ( $p$ for interaction $=0.38$ ).
Complementary analyses were run to explore the possibility of misclassification error due to change in the infant's status regarding bed-sharing over the course of the observation period. These analyses showed that $12.3 \%$ of the infants who were not bed-sharers at 3 months were so at 12 months; and among those who shared the bed with their mothers at 3 months of age $(46.0 \%)$, more than one third $(14.9 \%$ of the whole cohort) were reported to be non-bed-sharers at 12 months. To avoid the effect of this misclassification error on the effect estimates, the analyses were repeated considering four groups of infants: those who were bed-sharers at 3 and 12 months (always bedsharers) ( $n=1177)$; those who were not bed-sharers at 3 or at 12 months (never bed-sharers) $(n=1552)$; those who were bedsharers at 3 but not at 12 months $(n=557)$; and those who were not bed-sharers at 3 but were so at 12 months $(n=461)$. The results from these analyses showed that the incidence of admissions due to pneumonia decreased from $4.3 \%$ among the 'always bed-sharers' to $2.8 \%$ among those who never bedshared over the period $(p=0.02)$. Interaction between the pattern of bed-sharing and duration of breastfeeding ( $\leq 3$ months or $>3$ months) was present: the adjusted OR for 'non-breastfed always bed-sharers' was 95\% higher than for 'non-breastfed never bed-sharers', which was taken as the reference group ( $\mathrm{OR}=1.95 ; 95 \%$ CI 1.01 to 3.75 ). Among those who changed their exposure status, an intermediate $\mathrm{OR}$ was observed: 1.68 (95\% CI 0.79 to 3.57) for non-breastfed infants who quit bed-sharing after 3 months and 0.83 (95\% CI 0.27 to 2.54) for non-breastfed infants who became bed-sharers after 3 months, in comparison with 'non-breastfed never bedsharers', thus indicating that there was a dose-response effect from bed-sharing on the risk of admission due to pneumonia among non-breastfed infants ( $p$ for trend $=0.028$ ).

\section{DISCUSSION}

The main finding from this study was that infants who shared the bed with their mothers and were not breastfed presented a risk of hospitalisation due to pneumonia that was almost twice as high as among non-breastfed non-bed-sharers. The observed
Figure 1 Effect of bed-sharing on the risk of hospitalisation due to pneumonia between the ages of 3 and 12 months, according to the duration of breastfeeding.

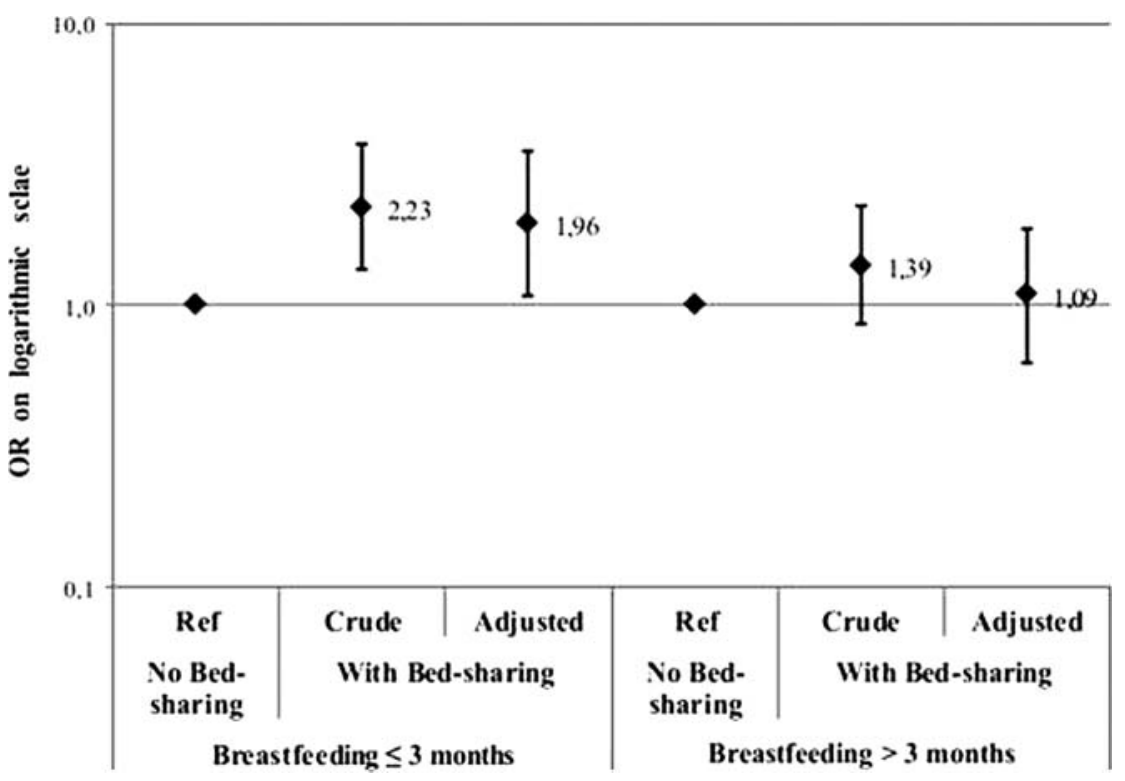


Table 1 Crude and adjusted OR for hospitalisation due to diarrhoea between the ages of 3 and 12 months

\begin{tabular}{lll}
\hline Bed-sharing & OR $(\mathbf{9 5 \%}$ CI) & p Value \\
\hline Crude & $2.04(1.00$ to 4.17$)$ & $0.044^{*}$ \\
Adjustedt & $1.44(0.62$ to 3.32$)$ & $0.392^{*}$
\end{tabular}

${ }^{*}$ Heterogeneity test.

†Adjusted for mother's age and schooling level, interval between deliveries, weight gain during pregnancy, total number of people living in the home, small for gestational age at birth, and Z-scores of weight-for-age and weight-for-length at 3 months of age.

interaction between breastfeeding and bed-sharing highlights the well-known protective effect of breastfeeding on child health. ${ }^{21} 22$ For instance, a case-control study conducted on the Pelotas Birth Cohort of 1993, showed that children who were not breastfed had a chance of hospitalisation due to pneumonia that was 17 times greater than among those who received maternal milk. ${ }^{23}$ Breastfeeding is associated with lower risks of morbidity-mortality, ${ }^{21} 2425$ particularly in relation to infectious diseases, and it even reduces the incidence of hospitalisation due to these causes. ${ }^{1326}$

The mechanism through which non-breastfed bed-sharers are put at higher risk of hospitalisation due to pneumonia may be similar to what has been indicated for respiratory diseases in general: the sharing of environments increases the risk of pneumonia because of the ease of pathogen transmission through breathing. $^{27}$

The strengths of this study include the population-based longitudinal design and the small proportion of losses during follow-ups. The limitations include the fact that information on bed-sharing and hospitalisations was obtained through the mothers' reports.

One additional limitation is that the real prevalence of bed-sharing may have been underestimated, because of the parents' concern either in relation to the social acceptance of this practice or in relation to its effects on the formation of the child's self-confidence and independence. Moreover, underreporting may be dependent on the type of advice received from healthcare professionals. However, in a cohort study conducted in Passo Fundo (another city in Southern Brazil), 67\% of the mothers reported that they had not received any type of recommendation in the maternity hospital regarding management of their infants' sleep, and $47 \%$ of the mothers had not received any advice in this regard during visits to well-baby clinics. ${ }^{3}$

In conclusion, this study showed that close physical proximity through bed-sharing with the mother does not lead to higher risk of hospitalisation due to pneumonia, provided that the infant is being breastfed, even after allowing for several potential confounders including the total number of people living in the home. No studies exploring this level of proximity (bed-sharing) between mother and infant were found in the literature, thus impairing comparisons with findings from different populations. Moreover, no mechanisms for transmission other than proximity were found in the literature. All young infants need close contact with a caregiver to survive. However, infants who share the bed to sleep are in even closer contact with the caregiver, thus facilitating transmission of infectious agents. Because of the implications for child healthcare that stem from advice given to mothers regarding management of their infants' sleep, further research is needed, particularly in settings with high prevalence of bed-sharing, in order to reinforce or refute the results observed here.

\section{What is already known on this subject}

Bed-sharing with the mother in infancy and childhood is a common sleeping practice in several countries. Studies on the effect of bed-sharing on the risk of hospitalisation due to pneumonia and diarrhoea in infancy are lacking in the literature.

\section{What this study adds}

- Non-breastfeeding bed-sharer infants presented higher risk of hospitalisation due to pneumonia. In settings where bed-sharing is common, health professionals should emphasise the importance of breastfeeding to prevent hospitalisation due to pneumonia.

\section{Policy implications}

- Protective effect over hospitalization due to pneumonia even among bed sharing infants may be added to the arguments in promotion of breastfeeding.

Acknowledgments This article is based on data from the 'Pelotas Birth Cohort, 2004' study, conducted within the Postgraduate Epidemiology Programme at the Federal University of Pelotas. The 2004 birth cohort study is currently supported by the Wellcome Trust, UK, through its programme of 'Major Awards for Latin America on Health Consequences of Population Change'. Previous phases of the study were supported by the World Health Organisation, National Support Programme for Centres of Excellence (PRONEX), the Brazilian National Research Council (CNPq), the Brazilian Ministry of Health and the Children's Mission.

Contributors KMAN participated in the design of the study and performed the statistical analysis. ISS conceived the study, participated in its design and coordination and helped to draft the manuscript. DAG, AJDB and AM participated in study design and coordination and helped to draft the manuscript. All the authors read and approved the final version of the manuscript.

Funding This work was supported by the Wellcome Trust, UK, through grant number 086974/Z/08/Z

\section{Competing interests None.}

Ethics approval Research Ethics Committee of the Federal University of Pelotas.

Provenance and peer review Not commissioned; externally peer reviewed.

Open Access This is an Open Access article distributed in accordance with the Creative Commons Attribution Non Commercial (CC BY-NC 3.0) license, which permits others to distribute, remix, adapt, build upon this work non-commercially, and license their derivative works on different terms, provided the original work is properly cited and the use is non-commercial. See: http://creativecommons.org/licenses/by-nc/3.0/

\section{REFERENCES}

1. Canadian Pediatric Society. Recommendations for safe sleeping environments for infants and children. Paediatr Child Health 2004;9:659-63.

2. Blair PS. Putting co-sleeping into perspective. J Pediatr (Rio J) 2008:84:99-101.

3. Geib LT, Nunes ML. Hábitos de sono relacionados à síndrome da morte súbita do lactente: estudo populacional. Cad Saúde Pública 2006;22:415-23.

4. Issler RM PJC, Giugliani ERJ . Infant sleep position. A randomized clinical trial of an educational intervention in the maternity ward in Porto Alegre, Brazil. Birth 2009;36:115-21.

5. Jenni $\mathbf{O G}$, Fuhrer $\mathrm{HZ}$, Iglowstein $\mathrm{I}$, et al. A longitudinal study of bed sharing and sleep problems among Swiss children in the first 10 years of life. Pediatrics 2005;115:233-40.

6. Blair $\mathbf{P}$, Ball H. The prevalence and characteristics associated with parent-infant bed-sharing in England. Arch Dis Child 2004;89:1106-10. 
7. Willinger $\mathbf{M}, \mathrm{Ko} \mathrm{CW}$, Hoffman $\mathrm{HJ}$, et al. Trends in infant bed sharing in the United States, 1993-2000: the National Infant Sleep Position study. Arch Pediatr Adolesc Med 2003;157:43-9.

8. McKenna JJ, Mosko S, Dungy C, et al. Sleep and arousal patterns of co-sleeping human mother/infant pairs: a preliminary physiological study with implications for the study of sudden infant death syndrome (SIDS). Am J Phys Anthropol 1990;83:331-47.

9. McKenna J, Mosco S, Richard C. Bedsharing Promotes Breastfeeding. Pediatrics 1997;100:214-19.

10. Santos IS, Mota D, Matijasevich A, et al. Bedsharing at 3 months and Breastfeeding at 1 year in southern Brazil. J Pediatr 2008;155:505-9.

11. Task Force on Sudden Infant Death Syndrome. Moon RY. SIDS and other sleep-related infant deaths: expansion of recommendations for a safe infant sleeping environment. Pediatrics 2011;128:1030-9.

12. Rudan I, Boschi-Pinto C, Biloglav Z, et al. Epidemiology and etiology of childhood pneumonia. Bull World Health Organ 2008;86:408-16.

13. Victora CG, Fuchs SC, Flores JAC, et al. Risk factors for pneumonia among children in a Brazilian metropolitan area. Pediatrics 1994;93:977-85.

14. Cardoso MRA, Cousens SN, Siqueira LFG, et al. Crowding: risk factor or protective factor for lower respiratory disease in young children? BMC Public Health 2004;4:19.

15. Holberg CJ, Wright AL, Martinez FD, et al. Risk factors for respiratory syncytial virus-associated lower respiratory illnesses in the first year of life. Am J Epidemiol 1991;133:1135-51

16. Baker D, Taylor $\mathrm{H}$, Henderson $\mathrm{J}$, et al. Inequality in infant morbidity: causes and consequences in England in the 1990s. J Epidemiol Community Health 1998 1998;52:451-8.

17. Blake PA, Ramos S, MacDonald KL, et al. Pathogen-specific risk factors and protective factors for acute diarrheal disease in urban Brazilian infants. J Infect Dis 1993:167:627-32
18. Santos IS, Barros AJ, Matijasevich A, et al. Cohort profile: the 2004 Pelotas (Brazil) Birth Cohort Study. Int J Epidemiol 2010;40:1461-8.

19. Dubowitz LMS, Goldberg C. Assessment of gestation by ultrasound in various stages of pregnancy in infants differing in size and ethnic origin. Int $J$ Obstet Gynaecol 1981:88:255-9.

20. Williams R, Creasy $R$, Cunningham $G$, et al. Fetal growth and perinatal viability in California. Obstet Gynecol 1982;59:624-32.

21. Victora CG, Smith PG, Vaughan JP, et al. Evidence for protection by breast-feeding against infant deaths from infectious diseases in Brazil. Lancet 1987:2:319-22.

22. Popkin BM, Adair L, Akin JS, et al. Breast-feeding and diarrheal morbidity Pediatrics 1990;86:874-82

23. César JA, Victora CG, Barros FC, et al. Impact of breast feeding on admission for pneumonia during postneonatal period in Brazil: nested case-control study. BMJ 1999;318:1316-20.

24. Bachrach VR, Schwarz E, Bachrach LR. Breastfeeding and the risk of hospitalization for respiratory disease in infancy: a meta-analysis. Arch Pediatr Adolesc Med 2003;157:237-43.

25. Nishimura T, Suzue J, Kaji H. Breastfeeding reduces the severity of respiratory syncytial virus infection among young infants: a multi-center prospective study. Pediatr Int 2009;51:812-16.

26. Cesar JA, Victora CG, Santos IS, et al. Hospitalização por pneumonia: influência de fatores socioeconômicos e gestacionais em uma coorte de crianças no Sul do Brasil. Rev Saude Publica 1997;31:53-61.

27. Savitha MR, Nandeeshwara SB, Pradeep Kumar MJ, et al. Modifiable risk factors for acute lower respiratory tract infections. Indian J Pediatr 2007;74 477-82. 